Çukurova Üniversitesi Mühendislik Mimarlık Fakültesi Dergisi, 31(2), ss. 379-390, Aralık 2016

Çukurova University Journal of the Faculty of Engineering and Architecture, 31(2), pp. 379-390, December 2016

\title{
Levent (Akçadağ-Malatya) Bölgesinin Tektono-Stratigrafisi
}

\author{
Selim SOLAK ${ }^{1}$, Ulvi Can ÜNLÜGENÇ ${ }^{12}$, Ahmet Can AKINCI ${ }^{2}$ \\ ${ }^{1}$ Vedat Kaya Gözlem Müşavirlik Firması, Kayseri \\ ${ }^{2}$ Çukurova Üniversitesi, Mühendislik Mimarlık Fakültesi, Jeoloji Mühendisliği Bölümü, Adana
}

Geliş tarihi: 13.06.2016 Kabul tarihi: 23.11.2016

$\ddot{\mathbf{O z}}$

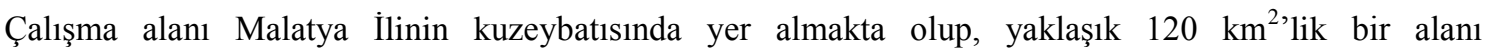
kapsamaktadır. Bölgede Üst Jura-Tersiyer yaş aralığında kayaçlar yüzeylemektedir. Levent ve çevresinin kaya stratigrafi birimleri ve tektono-stratigrafik özelliklerini belirlemek amacı ile yapılmış bu çalışmada 6 farklı litostratigrafi birimi ayırtlanarak haritalanmıştır. Bölgenin temel kayalarını Üst Jura-Alt Kretase yaşl1, aşırı derecede altere olmuş, kısmen tabakalı, gri-bej renkteki Horasançal Formasyonu oluşturmaktadır. Geç Kampaniyen sırası ve sonrasında olasılıkla kuzeyden güneye doğru bindirmeler ile gelen Hocalıkova ofiyoliti, temeldeki Horasanaçal Formasyonunu tektonik olarak üzerlemektedir. Geç Kampaniyen-Erken Mastrihtiyen'de tektonik aktivite ile denetlenen bir havzada transgresif olarak Ulupınar Formasyonu havzanın kenar kesimlerinde (sı̆̆ denizel-sahil çizgisi çökelleri) çökelmiştir. Ulupınar Formasyonunun üzerine; başlıca çakıltaşı, kumtaşı, kireçtaşı-marn ardalanmasından oluşan, Orta-Geç Eosen yaşlı ve genelde lagün, kumsal, şelf ortamlarında çökelen Tohma Formasyonu açısal uyumsuzlukla gelmektedir. Tohma Formasyonu üzerine yine uyumsuz olarak başlica bazaltlardan oluşan Orta-Geç Miyosen yaşlı Yamadağ volkanitleri gelmektedir. Bölgedeki en genç birimler olan Kuvaterner yaşlı alüvyon yelpazeleri ve alüvyonlar diğer bütün birimler üzerinde açısal uyumsuzlukla yer almaktadır.

Anahtar Kelimeler: Levent-Akçadağ, Tektono-stratigrafi, Malatya baseni

\section{Tectono-Stratigraphy of Levent (Akçadağ-Malatya) Region}

\begin{abstract}
The study area is located to the Northwest of Malatya city and covers an area of about 120 square km. Upper Jurassic-Tertiary aged formations are exposed around the region. This study aims to determine lithostratigraphic and tectonostratigraphic features of the units in Levent village and its near surrounding area where six lithostratigraphic units have been distinguished. The basement is represented by Late Jurassic-Early Cretaceous age Horasançal Formation which consists of fractured, partly bedded, grey to beige coloured limestone. The Hocalıkova ophiolites, which tectonically overlies the Horasançal Formation, probably thrusted into the area from north to the south during and/or after late Campanian. The Ulupinar Formation transgresivelly deposited to the edge of the basin (shallow marine-shore line sediments) during late Campanian-early Maastrichtian around the tectonically controlled basin. Upper Cretaceous Ulupinar formation consisting of conglomerate, sandstone, marl and limestone was deposited
\end{abstract}

\footnotetext{
${ }^{1}$ Sorumlu yazar (Corresponding author): Ulvi Can ÜNLÜGENÇ, ulvican@cu.edu.tr
} 
partly in a shoreline area and partly in very shallow marine environments. Middle-Upper Eocene age Tohma formation that generally deposited in lagoon, beach and shelf environments comprising mainly pebblestone, sandstone, limestone-marl rests on the Ulupınar Formation with an angular unconformity. Middle-Late Miocene age Yamadağ volcanics comprising mainly basalts unconformably rests on the Tohma Formation. Quaternary age alluvial fan and alluviums are the youngest sediments of the area and unconformably rest on all the older units.

Keywords: Levent-Akçadağ, Tectono-stratigraphy, Malatya basin

\section{GíRiş}

Yüksek Lisans tez çalışmasından türetilen bu makalede Levent (Akçadağ, Malatya batısı) ve civarının jeolojik özellikleri incelenmiştir. Çalışma bölgesi Malatya'nın yaklaşık $25 \mathrm{~km}$ kuzeybatısında yer almakta olup, $120 \mathrm{~km}^{2}$ 'lik bir alanı kapsamaktadır (Şekil 1). Bölgede yer alan başlıca yerleşim merkezleri; Levent nahiye merkezi, Ortaköy, Tataruşağ1, Kadiruşağı, Büyükköy, Kolköy, İncecik, Mezraaköy mahalleleridir.

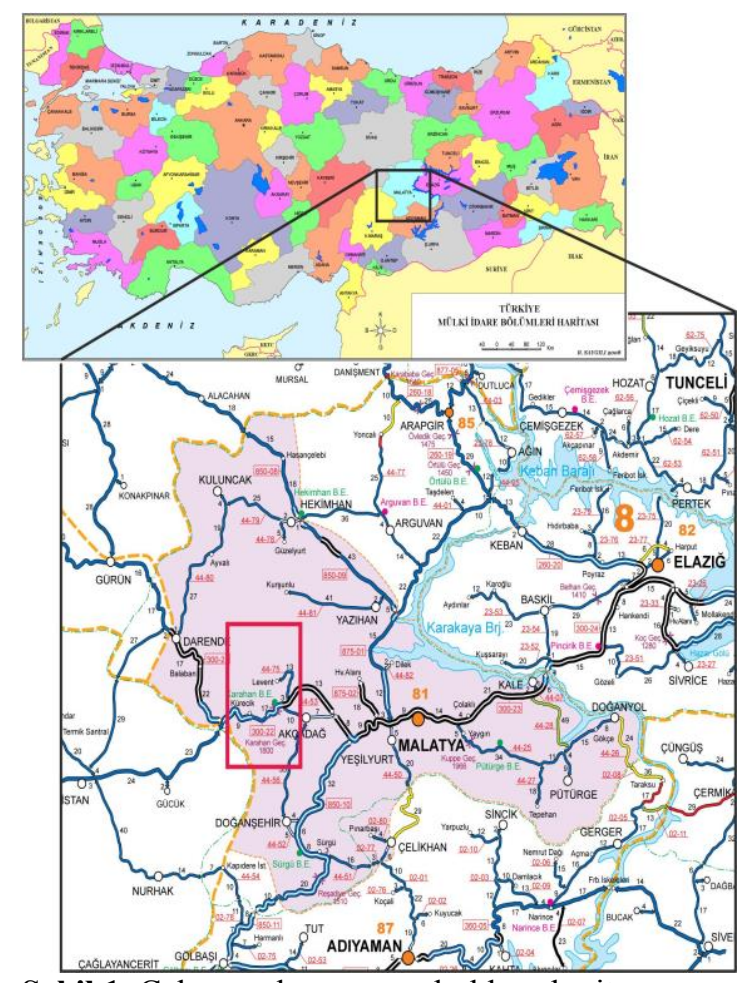

Şekil 1. Çalışma alanının yer bulduru haritası
- Qal: Genç Alüvyon (Kuvaterner),

- Tyd: Yamadağ Volkanitleri (Orta-Üst Miyosen),

- Tt: Tohma Formasyonu (Orta-Üst Eosen),

- Tti: İriağaç Üyesi (Üst Eosen),

- Ttçi: Çivril Üyesi (Üst Lütesiyen),

- Ttç: Çorak Üyesi (Üst Lütesiyen),

- Tty: Yoğunsakız Üyesi (Alt-Orta Lütesiyen),

- krüu: Ulupınar Formasyonu (Mastrihtiyen),

- krüh: Hocalıkova Ofiyoliti (yerleşimi Geç

Kampaniyen),

- J-Kh: Horasançal Formasyonu (Jura-Alt

Kretase),

- Ttz: Zeynepoğlu Üyesi (Alt Lütesiyen).

Bu çalışmada 1/25.000 ölçekli Malatya L39 b1, b4 topografik harita paftaları içerisinde yer alan inceleme bölgesinde yüzeyleyen kaya birimleri ve yapısal unsurlar incelenmiş, bu araştırma sonucunda, veriler topografik harita üzerine işlenerek, bölgenin jeolojik haritası yapılmıştır. İnceleme bölgesinden toplanan örnekler ince kesit haline getirilip, mikroskop altında mineralojik özellikleri ile tanımlanabilen fosil formları incelenerek yaşları belirlenmiştir.

Çalışma bölgesi, Malatya-Ovacık Fay Zonu'nun yakın batı kesiminde bulunması ve bu fay zonundan etkilenildiği düşünülerek çalışma sahası olarak seçilmiştir. Araştırma bulgularında da belirtileceği üzere, yapılan arazi çalışmaları sırasında fazla sayıda tektonik etkileri gösterecek verilere rastlanılamamıştır. Öncelikli olarak arazide belirli yönlerde gelişmiş olan dikçe şevliklerin tektonik kontrollü olarak geliştiği düşünülmekteydi. Ancak, yapılan jeolojik incelemelerde, üst kesimlerde kalan sert-katı kayaçların alt kesimlerinde bulunan yumuşak birimlerin aşınıp boşalması nedeniyle kaya-blok 
düşmeleri şeklinde gelişmiş sarplıklardan oluştukları belirlenmiştir.

\section{MATERYAL VE METOT}

İnceleme alanı Doğu Anadolu Bölgesinde Malatya İli sınırları içerisinde yer almakta olup, Akçadağ İlçesinin yakın kuzeybatısında yaklaşık $120 \mathrm{~km}^{2}$ 'lik bir alanı kapsamaktadır.

Bölge engebeli bir arazi yapısına sahiptir ve yer yer derin vadilere sahip olup, ağaçlık alanlar seyrektir. İnceleme alanının kuzey kesiminde Tohma Çayı akmaktadır. 1/25.000 ölçekli jeolojik haritanın, enine kesitlerin, örnek ve fotoğraf yerini gösteren haritanın, yapı haritasının ve diğer bütün şekillerin çiziminde bilgisayar destekli çizim programı kullanılmıştır. Ayrıca makale içerisinde ve eklerinde kullanılan kısaltmalar, simgeler ve diğer işaretler toplu olarak aşağıda verilmiştir;

\section{ARAȘTIRMA BULGULARI}

\subsection{Stratigrafi}

İncelenen alandaki stratigrafik istif Mesozoyik, Senozoyik ve Kuvaterner yaşlı formasyonlardan oluşmaktadır. Çalışma alanı ve yakın çevresinin temelinde Üst Jura-Alt Kretase yaşlı çörtlü ve mikritik kireçtaşlarından oluşan Horasançal Formasyonu bulunmaktadır. Horasançal Formasyonu çalışma sahasının güney kesiminde geniş bir alanda mostra vermektedir (Şekil 2 ve 3).

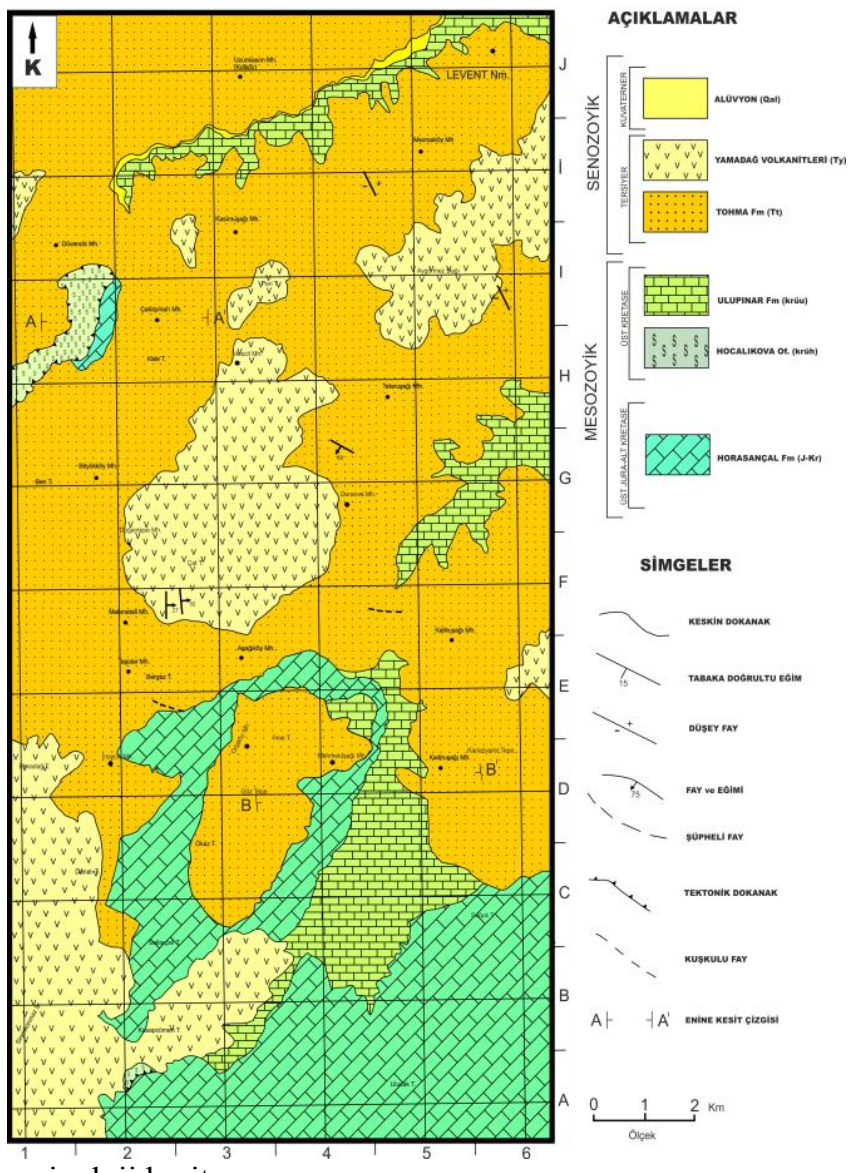

Şekil 2. Çalışma alanının jeoloji haritası 

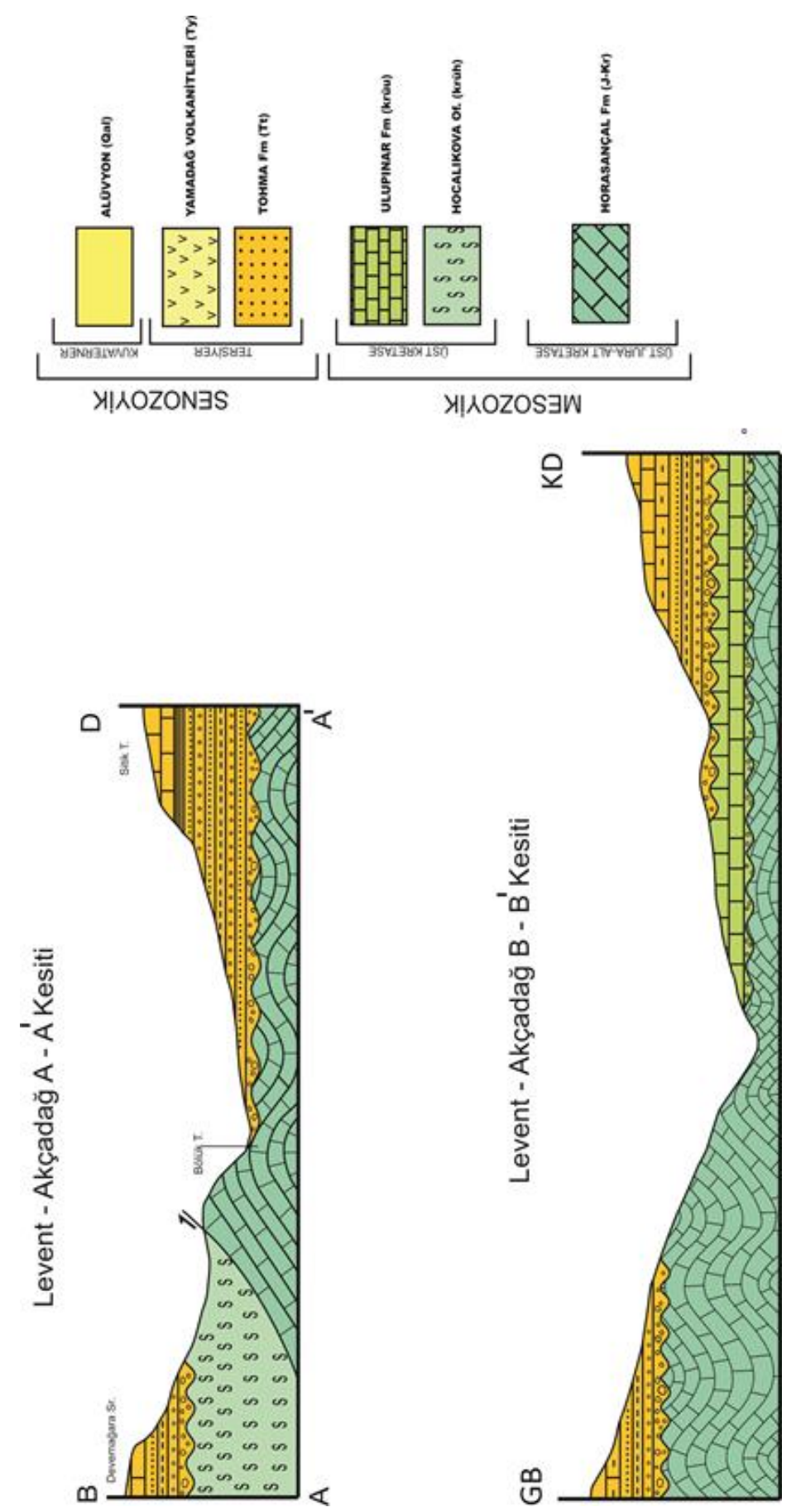

Şekil 3. İnceleme alanından alınmış enine kesitler (kesit güzergahları Şekil 2 üzerinde gösterilmiştir)

Horasançal Formasyonun üzerine tektonik piroksenitlerden oluşan Üst Kretase yaşlı dokanakla serpantinitler ve serpantinitleşmiş Hocalıkova ofiyoliti gelmektedir. Üst Kretase yaşlı 
Ulupınar Formasyonu ise bu birimleri uyumsuz olarak örtmektedir (Şekil 4). Geç Kretase'nin son evresinde oluşan bu birim ilk olarak Kırankaya kalkerleri olarak adlandırılmıştır [1]. Kaba klastiklerden oluşan Ulupınar Formasyonu Horasançal Formasyonun üzerine açısal uyumsuzlukla gelmektedir. Ulupınar Formasyonu genellikle alacalı, kırmızı renkli konglomera, kumtaşı, kumlu marn ve şeyl ardalanması halindeki kaba klastiklerden oluşmaktadır. Ulupınar Formasyonunun kaba klastiklerinin üst kesimlerinde birim dereceli olarak rudistli kireçtaş1 fasiyesine geçmektedir.

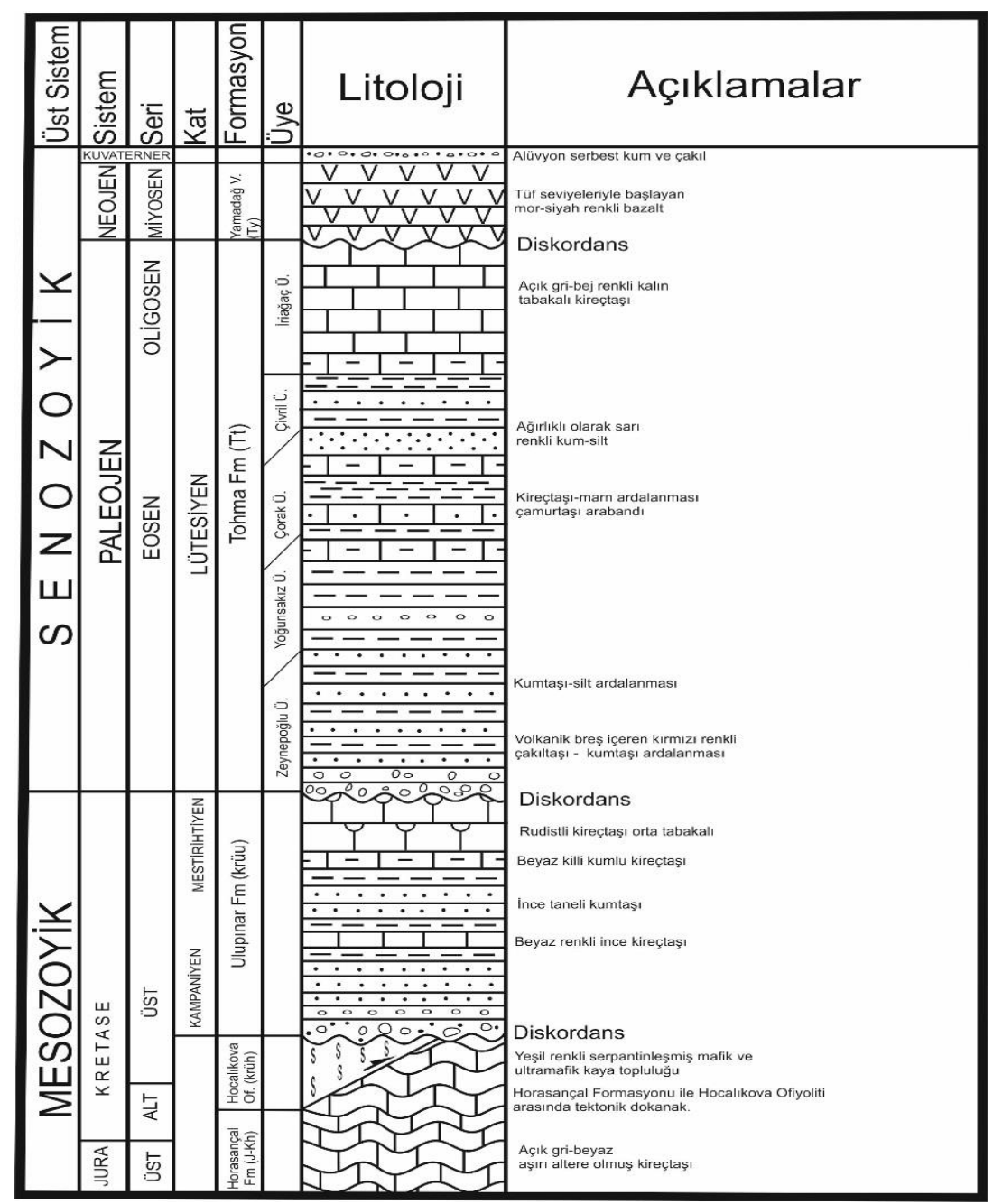

Şekil 4. Levent Akçadağ bölgesinin genelleştirilmiş stratigrafik kesiti (Ölçeksiz)

Ulupınar Formasyonu üzerine aşınma yüzeyi ile Tersiyer yaşlı Tohma Formasyonu gelmektedir. Tohma Formasyonu; Zeynepoğlu Üyesi, Yoğunsakız Üyesi, Çorak Üyesi, Çivril Üyesi ve İriağaç Üyesi olmak üzere 5 üyeden oluşmaktadır [2]. Bu çalışma kapsamında inceleme bölgesinde yüzlek veren bazı üyelerin adları isim kargaşası yaratmamak üzere aynı şekilde kullanılmıştır.

Tohma Formasyonu üzerine Tersiyer yaşlı

Yamadă̆ Volkanitleri gelmektedir. Beyaz renkli tüfitler üzerinde koyu mor-siyah renkli bazaltlardan oluşan birimin alterasyona uğramış 
kısımları kahve renge sahiptir. Bölgedeki en genç birimler Kuvaterner yaşlı alüvyonlardır [2]. Özellikle Tohma nehri kıyısında güncel çökelleri görmek mümkündür.

\subsubsection{Horasançal Formasyonu (J-Kh)}

İnceleme alanında temeli oluşturan Horasançal Formasyonu, çalışma sahasının özellikle güney kesimlerinde geniş mostralar vermektedir. Horasançal Formasyonu, masif yapılı aşırı derecede altere olmuş açık gri veya beyaz renkte olan kireçtaşı litolojisinden oluşmaktadır.

Çatlaklı bir yapıya sahip olan birimin bazı kesimlerinde gözlenen çatlaklar kalsitle doldurulmuştur. İnceleme sahasında temeli oluşturan bu formasyonun taban kesimi görülememektedir.

Horasançal Formasyonu, açık gri veya bej renkli, orta kalın tabakalanmalı, mikritik kireçtaşından ibaret olup, mostra veren yüzeylerinde genelde belirgin tabakalanma sunmamaktadır. Oldukça sert, sağlam ve dayanımlı görünen birim açılmış bulunan vadi boyunca sarp bir görünüm sunmaktadır. Birimin taban kesimi gözlenemediğinden dolayı kalınlığı bilinememektedir. Jura-Kretase yaşlı Horasançal Formasyonun üzerine çalışma sahasının güney kesiminde Mastrihtiyen yaşlı Ulupınar Formasyonunun kırıntılı çökelleri açısal uyumsuzlukla gelmektedir (Şekil 5). Ancak, yer yer yalnızca rudist içeren kireçtaşı seviyeleri onlap olarak temel birim üzerinde gözlenmektedir [3].

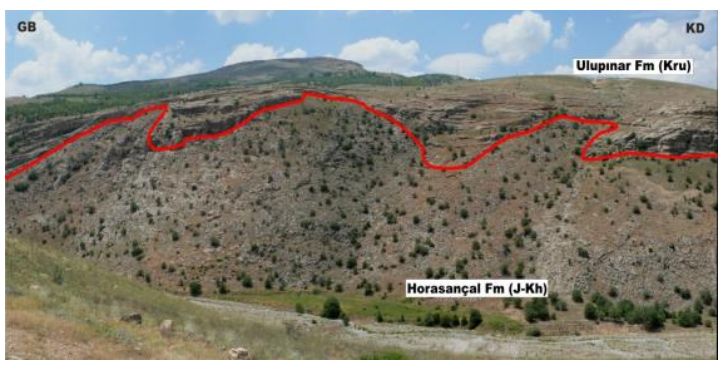

Şekil 5. Mehmetuşağı Mahallesi bölgesindeki JuraKretase yaşlı Horasançal Formasyonu üzerinde açısal uyumsuzlukla bulunan Mastrihtiyen yaşlı Ulupınar Formasyonu

\subsubsection{Hocalıkova Ofiyoliti (krüh)}

İnceleme alanında okyanusal kabuğa ait olan Hocalıkova Ofiyoliti (krüh) ultramafik ve mafik kayaların büyük çoğunluğu serpantinleşmiş harzburjit, piroksenit, gabro, spilit ve pelajik çökellerden oluşan kaya topluluğundan oluşmaktadır. Hocalıkova Ofiyolitini oluşturan ultramafik kayaçlar genellikle yeşil renkte olup, genelde kümülatif kayaçlarla temsil edilmekte ve genelde çalışma sahasının kuzey kesimindeki Bölük Tepe civarında yüzeylemektedir. Birim, sahada belirgin rengi ve ana mineralleri ile diğer litolojilerinden kolaylıkla ayırt edileblilmektedir. Hocalıkova Ofiyoliti (krüh) çalışma alanında genelde yeşil ve yeşilin diğer tonlarında gözlenmektedir [4]. Ayrışmamış yüzeylerde olivin ve piroksen kristalleri gözle seçilebilmektedir. Ultramafik kümülatlar ana minerallerini olivin ve piroksenin oluşturduğu dunit, harzburjit ve piroksenit ile temsil edilir. Birim genellikle çalışma sahasının kuzey kesimlerindeki Mollauşağı Mahallesi civarında geniş bir mostra sunmaktadır. Hocalıkova ofiyoliti, Büyükköy civarlarında sinırlı bir bölgede Jura-Alt Kretase yaşlı Horasansal Formasyonunu tektonik dokanak ile üzerlemekte olup (Şekil 6), KampaniyenMastrihtiyen yaşlı Ulupınar Formasyonu tarafindan uyumsuzlukla üzerlenmektedir.

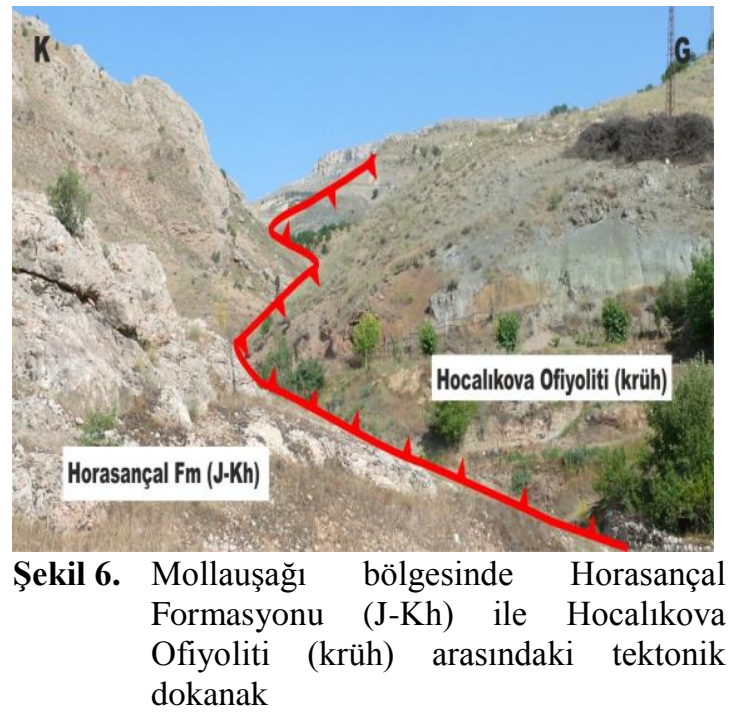




\subsubsection{Ulupınar Formasyonu (krüu)}

Ulupınar Formasyonu genellikle alaca, kırmızı renkli konglomera, kumtaşı, kumlu marn ve marn ardalanmasından oluşmaktadır (Şekil 7). Konglomera ve kumtaşı tabakaları elle ufalanabilecek derecede gevşek çimentoludur. Konglomera ve kumtaşları yeşil kayaç ve masif kireçtaşı parçalarını içermektedir. Kırmızı rengi de kapsadığı yeşil kayaç tanelerinden ileri gelmekte olup, özel rengi ile sahada kolaylıkla tanınır. Kumtaşları orta $(0,50-0,25 \mathrm{~mm})$ ve iri $(1,00-0,50 \mathrm{~mm})$ tanelidir. Tane büyüklükleri ve tabaka kalınlıkları alttan üste doğru küçülür. Tane dizilişi ve tanelerin yuvarlaklaşması oldukça iyi geliş̧ş̧̧ir.

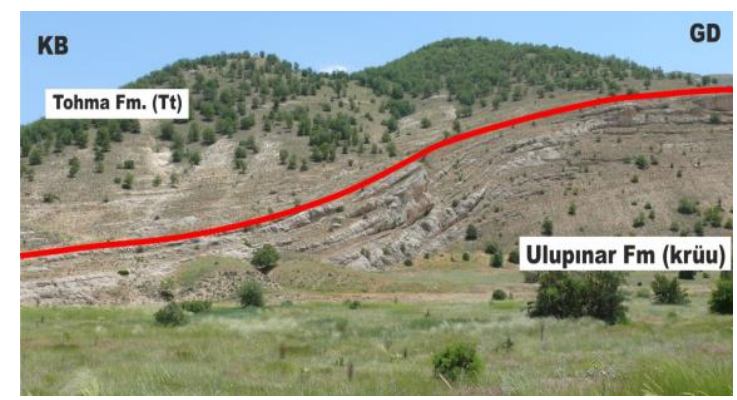

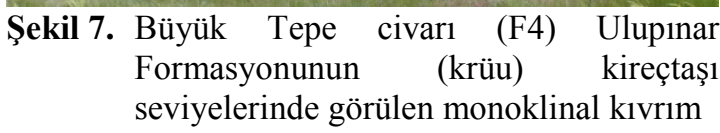

Formasyon, çalıșma sahasıının kuzey kesimlerinde ofiyolitik seri üzerine transgresif olarak gelmektedir. Konglomera ve kumtaşı tabakaları elle ufalanabilecek derecede zayıf çimentoludur. Birim, fosil kapsamı bakımından oldukça zengindir. Gerek inceleme alanımızdaki, gerekse çevredeki mostraları bol miktarda aşă̆ıdaki fosilleri kapsar [1]:

\section{Hippurites (Vaccinites) ultimus Milovanovic Cyclolites sp. \\ Actaeonella sp. \\ Orbitoides apiculata Schlum. \\ Orbitoides media d'Arch. \\ Loftusia sp.}

Ulupınar Formasyonu, tabanda Üst Jura-Alt Kretase yaşlı Horasançal Formasyonu üzerinde açısal uyumsuzlukla bulunur (Şekil 8). Birimin taban kesimlerinde gözlenen konglomera çakılları, alttaki Horasançal Formasyonundan türemiş olup, birim üzerinde transgresif olarak bulunmaktadır [5].

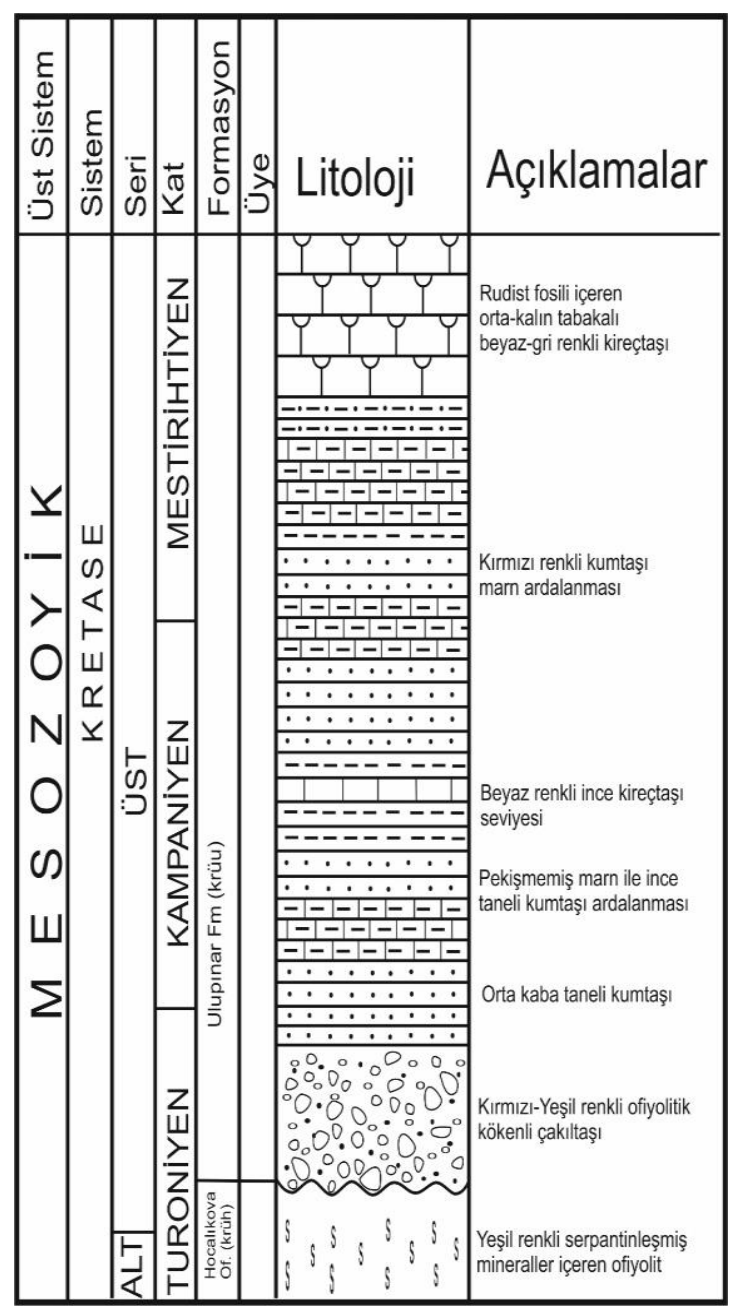

Şekil 8. Üst Kretase yaşlı Ulupınar Formasyonun genelleştirilmiş stratigrafik kesiti

Ulupınar Formasyonu Hocalıkova Ofiyolitinin üzerinde, tektonizmanın sıkışmalı rejimden gerilmeli rejime dönüşmesi sonucu faylarla denetlenen bir havzada çökelmiş olmalıdır. Kırıntı malzeme gelişinin zayıf olduğu kıyı kesimlerinde ve yersel yükseltiler üzerinde Rudistli kireçtaş1 seviyeleri çökelmiştir. 
Gerek Foraminifer topluluğu ve gerekse içerdiği Ostrakod'lar Ulupınar Formasyonu'nun yaşını Mastrihtiyen olarak vermektedir. Ulupınar Formasyonu, Hocalıkova ofiyolitinin bölgeye yerleşiminden sonraki dönemde meydana gelen bir kalınlaşıp yükselme ve yükselmeyi izleyen erozyonun ürünü olarak oluştuğu düşünülmektedir [6].

\subsubsection{Tohma Formasyonu ( $\mathrm{Tt})$}

Tohma Formasyonu içerdiği mikro ve makrofosil topluluklarının yaşama ortamları ve çökel özelliklerine göre lagün, kumsal, sığ ve açık şelf ortamlarında çökelmiştir [3].

Tohma Formasyonundaki üyeler alttan üste doğru; çakıltaşı, kumtaşı çamurtaşı ardalanması (Zeynepoğlu üyesi); tabanı çakıltaşı-kumtaşı seviyeli kireçtaşı-marn ardalanması (Yoğunsakız üyesi); çamurtaş1-kumtaşı-killi kireçtaş1 ardalanması (Çorak üyesi); marn-kireçtaşı ardalanması (Çivril üyesi) ve alt düzeyi marn arakatkılı masif kireçtaşından (İriağaç üyesi) ibaret 350-850 metre arasında kalınlık sunan istiften oluşmaktadır [3].

\subsubsection{Zeynepoğlu Üyesi (Ttz)}

Birim tabanda kahverengi ve bordo rengin hâkim olduğu çakıltaşları ve kumtaşları ile başlamaktadır. Çakıl-blok türü bileşenlerin boyları 2-45 cm arasında değişmekte olup, çok kötü boylanmalı ve gevşek çimentolu bir yapı sunmaktadır. İçerdiği taneler bakımından genelde volkanik kökenli kayaçlardan türemiş (bazalt, andezit gibi) çakıllar ile çok az miktarda da Horasançal Formasyonuna ait çakıl parçalarını kapsamaktadır. Birim gevşek bir çimentolanma ile bağlandığından arazide kolaylıkla aşınmaya maruz kalmıştır. Ortaköy civarında onlap olarak gelen bu birimlerde bu çakıllı seviye bir temel olup bunların üzerine Lütesiyen yaşlı karbonat - kırıntılı karbonat içeren bir istif gelmektedir [7,8].

Birimin, Akkuş [1] tarafından Darende-Balaban havzalarında yapmış olduğu çalışmalar sırasında ayırtlamış olduğu Alt Eosen yaşlı Korgantepe
Formasyonu ile litolojik ve yaş olarak eşdeğer olduğu düşünülmektedir [2].

\subsubsection{Yoğunsakız Üyesi (Ttz)}

Birim tabanda ardalanmalı olarak orta-iyi boylanmış, az pekişmiş yer yer çapraz tabakalanmalı açık gri renkli çakıltaşları ile başlamakta, üzerine az-orta pekişmiş, ince-orta tabakalanmalı, yer yer laminalı, sarımsı renkli gastropodlu ve lamellibranşlı kumtaşları ile devam etmekte, üzerine ise bol foraminiferli iyi pekişmiş, orta-yer yer kalın tabakalı, sar1-kirli sarı renkli kireçtaşları ile istif tamamlanmaktadır. Kireçtaşları az pekişmiş, açık gri renkli ince-orta kalınlıkta marn tabakaları ile ardalanmalı olarak gözlemlenmiştir. Birim tabanda yanal ve düşey geçişli olarak Zeynepoğlu üyesini üzerler, tavanda ise konkordan olarak düşey geçişle Çivril üyesi ve yine yanal düşey geçişle Çorak üyesine geçiş gösterir.

Elde edilen fosillere göre birimin yaşını Orta Eosen (Alt-Orta Lütesiyen) olarak belirlenmiştir [2]. Birimin çökelme ortamı fosil kapsamı, stratigrafik özellikleri ve sedimantolojik veriler ışığında plaj-sı̆̆ deniz ortamı olmalıdır. Birim içerisinde gözlemlenen çapraz tabakalı çakıltaşları ve kumtaşları muhtemelen plaj ortamını göstermektedir. Gastropod ve lamellibranşların varlığı plaj ortamını destekler niteliktedir. $\mathrm{Su}$ derinliğin artması ile birlikte kumtaşları yerini yanal geçişle kireçtaşı-marn ardalanmasına bırakır ve sı ̆ deniz konumuna geçer. Kireçtaşları içerisindeki mikrofosiller (Nummulites ve Alveolina) resif gerisi fasiyesini karakterize etmektedir.

\subsubsection{3. Çorak Üyesi (Ttç)}

Çorak Üyesi 10-60 m arasında değişim gösteren bir kalınlık sunar. Çorak üyesi, tabanda az tutturulmuş, ince tabakalanmalı yer yer laminalanmalı kırmızı renkli jips mercekli çamurtaşları ile başlamaktadır. Üzerine az pekişmiş, orta tabakalanmalı, gri renkli yer yer açık sarı renkli kumtaşları ile davam eden istif, iyi pekişmiş ince-orta tabakalanmalı, sarı-kirli sarı 
renkli killi kireçtaşlarının ardalanması ile devam etmektedir. Birim, Yoğunsakız üyesi üzerine uyumlu-geçişli olarak gelmektedir. Birim üste doğru ise Çivril üyesine de yanal ve düşey geçişle geçmektedir. Birim içerisinden alınan sistematik örnekler içerisinde sadece killi kireçtaşı içerisinde fosillere rastlanılmıştır [2].

Birim, sedimantolojik veriler 1şı̆̆ında lagünel bir ortamı karakterize etmekle birlikte muhtemelen yersel tektonik hareketlerin etkisi ile zaman zaman sı̆̆ deniz ortamına geçmesi ile birlikte karbonat çökeliminin gerçekleştiği düşünülmektedir. Kumtaşlarının çok ince çamurtaşı laminaları içermeleri, iki farklı çökelme şekli bize bölgenin gelgit etkisi altında kaldığını göstermektedir.

\subsubsection{4. Çivril Üyesi (Ttçi)}

Birim, dayanımsız, yer yer laminalı, paralel tabakalanmalı, gri-açık sarı renkli marn ve iyi pekişmiş orta-kalın tabakalanmalı sarımsı renkli kireçtaşı ardalanmasından oluşmaktadır.

Birimin yaşı Üst Lütesiyen olarak belirlenmiştir. Çivril üyesinin çökelme ortamı, marn ve kireçtaşlarının varlığı, içerdiği fosil kapsamı göz önüne alındığında birim sı ̆ deniz (resif gerisi) ortamında çökelmiş olduğu belirtmektedir [2].

\subsubsection{6. İriağaç Üyesi (Tti)}

Birim, iyi pekişmiş masif, yer yer kalın-çok kalın tabakalanmalı, gri-sarımsı arası değişen renkte, fosilli kireçtaşları ile dayanımsız, ince-orta tabakalanmalı, açık sarımsı-kavrengi renkli killi kireçtaşı ardalanmasından oluşmaktadır. Birim özellikle sahada oluşturduğu yüksek tepeler ve bilhassa bu tepelerin düz olarak görülmesiyle kolay tanınabilmektedir.

Altında konkordan olarak Tohma Formasyonunun (Tt) Çivril Üyesi (Ttçi) bulunmakta olup, üzerine ise uyumsuzlukla Yamadağ Volkanitleri (Ty) gelmektedir. $\mathrm{Bu}$ alan genellikle çalışma alanının kuzey kesimlerindeki en yüksek yerlerini oluşturmaktadir.

\subsubsection{Yamadağ Volkanitleri (Ty)}

Koyu mor-siyah renkli Yamadağ volkanitleri, açık renkli tüfitler üzerine gelen birim, tabanda bazaltik bileşimli lav akıntıları ile başlamakta olup, üste doğru piroklastikler ve bazaltik ve andezitik lav akıntıları ile son bulmaktadır.

Alteresyona uğramış kısımları kahverengi bir renge sahiptir. Oldukça sert ve dayanıklıdır. Genelde porfirik dokuludur. Yamadağ volkanitleri iki evrede oluşmuşlardır; birinci evre iri plajiyoklaz ve olivin fenokristalli bazaltlarla temsil edilirken, ikinci evre iri plajiyoklaz, olivin ve piroksen fenorkistalli bazaltlarla karakterize edilmektedir [4].

Yamadağ Volkanitlerinden (Ty) alınan örneklerin ince kesit çalışmasında Prof. Dr. Fikret İŞLER bazalt örneğinin mikrolitik porfirik dokuda olduğunu belirtmiştir. Plajyoklaslar mikrolitler şeklinde olup, ince uzun prizmatik şekildedirler. Diğer plajyoklasların görünümü nadiren feno-kristal şeklinde görülmektedir. $\mathrm{Bu}$ feno-kristaller kırıklı bir yap1 sunduğundan dolay1 birimin yerleşmesi sırasında muhtemelen tektonizmadan etkilenmiş olduğu düşünülmektedir. Bazı plajiyoklaslarda zonlu yapı görülmektedir (Şekil 9).
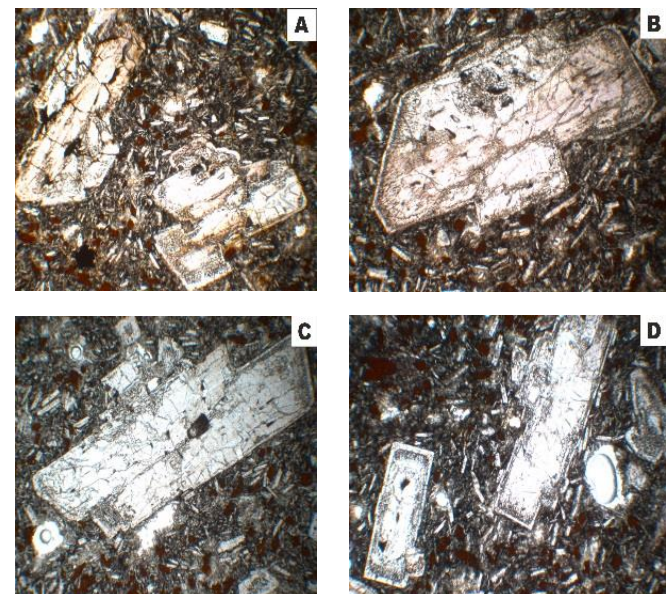

Şekil 9. Yamadağ Volkanitlerinden alınan ince kesit örnekleri içerisinde kırmızı renkli olivin, mikrolit şeklinde plajiyoklas ve fenokristal plajiyoklas 
Olivin minerali genellikle küçük taneler şeklinde bolca görülmekte olup seyrek olarak iri tanedirler. Fakat bunların tamamı demirle ayrışım geçirerek iddingsit halini almışlardır, kırmızı renkte olmalarıyla dikkat çekmektedirler.

\subsubsection{Alüvyon (Qal)}

Genellikle Tohma Nehri boyunca görülen pekişmemiş silt, kil, kum kaba kumtaşı ve çakıltaşlarından oluşmaktadır. Birim, çalışma sahasının özellikle kuzey kesimlerinde sık görülmektedir.

\section{YAPISAL JEOLOJI}

\subsection{Bölgesel Tektonik}

Çalışma alanı tektonik açıdan oldukça aktif bir bölge içerisinde yer almakta olup çok sayıda fay ve fay zonu içermektedir (Şekil 10). Çalışma alanı içerisinde en önemli fay Aktimur'un 1979 yılında uydu görüntülerinden ve hava fotoğraflarından yararlanarak "Malatya Fayı" olarak isimlendirdiği Malatya-Ovacık Fay Zonudur. Çalışma sahasında yaklaşık K30D doğrultulu olarak uzanan MalatyaOvacık Fay Zonunun (Şekil 10) Pliyosen'den genç bir fay olduğu belirtilmekte [9-11] olup, fayın diri ya da pasif bir fay olduğu yönünde farklı görüşler ortaya atılmaktadır. Bu konuda, Aktimur [9] ile Koçyiğit ve Beyhan [10] Malatya-Ovacık Fay Zonunun halen aktif bir fay olduğu yönünde fikir öne sürerlerken, Westaway ve Arger [11] ise onlara tam zit fikir öne sürüp, Malatya-Ovacık Fay Zonu'nun diri fay olmadığını ve bu fayın 3-5 milyon yıl önce (Doğu Anadolu Fay Zonu'nun gelişiminden önce) aktif bir fay olduğunu belirtmișlerdir. Doğu Anadolu Fay Zonunun gelişmesi ile birlikte fayın etkinliğinin durduğunu öne sürmüşlerdir. Doğrultu atımlı sol yanal bir fay olarak uzanan Malatya-Ovackk Fay Zonu $[9,12,13]$ Doğanşehir ilçesinin yaklaşık $5 \mathrm{~km}$, güneybatısından başlamakta ve çalışma sahasının yaklaşık $10 \mathrm{~km}$, doğusundan uzanımına devam ederek kuzeyde Arapkir İlccesi'nin 10 km, batısında çatallandığı ve birinci çatalın kuzeye doğru Ilıç'ın $15 \mathrm{~km}$, güneybatısına kadar uzandığını ve diğer çatalın kuzeydoğuya doğru yaklaşık $25 \mathrm{~km}$ uzanmakta olduğu Şaroğlu ve arkadaşları [13] tarafindan da ileri sürülmektedir.

Malatya ili civarında olan deprem kayitlarına bakıldığında da Malatya-Ovacık Fay Zonuna ve bölgedeki diğer küçük ölçekli faylara bağlı olarak gelişmiş olan küçük ölçekli deprem kayıtları bulunmaktadır. Bu verilere de dayanarak MalatyaOvacık Fayının aktif bir fay olabileceği fikri öne çıkmaktadır [14].

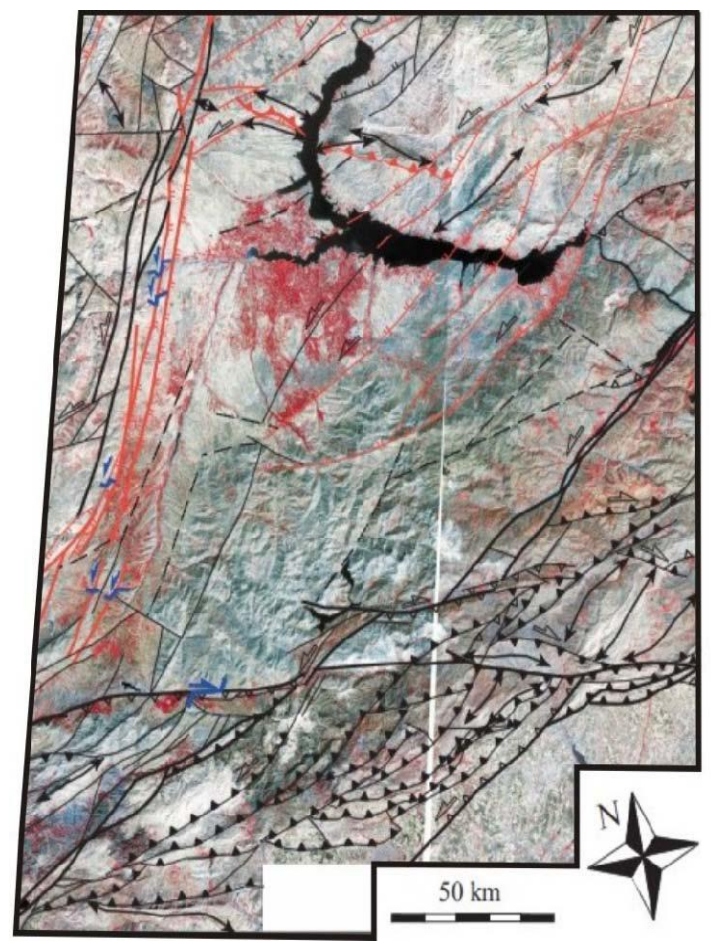

Şekil 10. İnceleme alanının uzaktan algılama yöntemiyle çizgisellik analizleri ile birlikte yapısal unsurların işlenmesi sonucu elde edilmiş Malatya-Ovacık Fay zonunun bir kısmının uydu görüntüsü üzerinde işlenmiş yapısal haritas1 [12]

\section{SONUÇLAR}

Çalışma sahası içerisinde yüzeyleyen 6 farklı birim ayırtlanarak incelenmiş ve bölgenin $1 / 25.000$ ölçekli jeoloji haritası, jeoloji enine kesitleri ve genelleştirilmiş stratigrafik kesiti hazırlanmıştır. 
Çalıșma sahasındaki en yaşlı birimin Üst Jura-Alt Kretase yaşlı Horasançal Formasyonu olduğu saptanmıştır.

Gürer, [5]'in Hekimhan-Hasançelebi yöresinde "Karapınar Formasyonu" olarak tanımladığı Üst Kretase yaşlı birimin çalışma sahasında ayırtlamış olduğumuz Mastrihtiyen yaşlı Ulupınar Formasyonu karşılığı olduğu sonucuna varılmıştır. Ayrıca, litolojik ve paleontolojik özellikler göz önüne alındığında Sevimli [2]'nin Yazıhan (Malatya) Batısında ayırtlayarak tanımladığı ve Üst Kretase yaşını verdiği Hekimhan Formasyonun da bu çalışma kapsamında Akkuş [1]'un çalışmasında tanımladığı "Ulupınar Formasyonu”nun eşdeğeri olduğu ortaya konulmuştur.

Çalışma sahasında yaklaşık Kuzeydoğu-Güneybatı yönelimli olarak gelişmiş olan dikçe şevliklerin fay kontrollü olduğundan ziyade, üst kesimlerde kalan sert-dayanımlı kayaçların alt kesimlerindeki yumuşak birimlerin aşınıp, tabanlarının boşalması nedeniyle, kaya-blok düşmeleri şeklinde geliştiği sonucuna varılmıştır.

Gürbüz ve Gül [6]'ün Darende-Balaban bölgesinde ayırtladıkları Üst Kretase yaşlı Ulupınar Formasyonunun taban seviyelerinde ayırtlayarak haritaladıkları "Tohma resiflerinin", inceleme bölgesinde Üst Kretase yaşlı Ulupınar Formasyonunu uyumsuzlukla üzerlediği ve yaşının da Eosen-Alt Miyosen olduğu sonucuna varılmıştır.

\section{TEŞEKKÜR}

Bu çalışma Çukurova Üniversitesi, Bilimsel Araştırma Projeleri birimi tarafından MMF2009YL45 numaralı proje kapsamında desteklenmiştir. İnce kesitlerin mikroskopta değerlendirmesinde katkı koyan Prof. Dr. Fikret İSLER; fosil tanımlamaları ve yaş tayinlerinde yardımcı olan Prof. Dr. Niyazi AVŞAR'a teşekkür ederiz.

\section{KAYNAKLAR}

1. Akkuş, F.M., 1971. Darende-Balaban Havzasındaki (Malatya, DGD Anadolu) Litostratigrafik Birimler ve Jipsli Formasyonların Yaşı Hakkında Yeni Bilgiler, M.T.A. Dergisi No:76, 60, Ankara.

2. Sevimli, U.I., 2009. Yazıhan (Malatya) Batısının Tektono-Stratigrafisi Ç.Ü. Fen Bilimleri Enst., Doktora Tezi, 159, Adana.

3. Örçen, S., 1984. Medik-Ebreme (KB Malatya) Dolayının Biyostratigrafisi ve Paleontolojisi, M.T.A. Raporu, Ankara.

4. Alparslan, M. ve Terzioğlu, N., 1996. Arguvan (Malatya K.) Yöresinde Üst Miyosen ve Pliyosen Yaşlı Volkaniklerin Karşılaştırılmalı Jeokimyasal Özellikleri, TJK Bülteni, 39, 2, 75-86, Ankara.

5. Gürer, Ö.F., 1994. Hekimhan-Hasançelebi yöresinin Üst Kretase Stratigrafisi ve Havza Evrimi: Türkiye Jeoloji Bült. 37/2, 135-149, Ankara.

6. Gürbüz, K., Gül, M., 2005. Evolution of and Factors Controlling Eocene Sedimentation in the Darende-Balaban Basin, Malatya (Eastern Turkey), Turkish Journal of Earth Sciences, vol. 14, p. 311-335

7. Gürbüz, K., Taptık, A., 2001. Sedimentological Evolution of Southern Part of the DarendeBalaban Basin (Yenice Darende area, Malatya, Eastern Turkey). $4^{\text {th }}$ International Turkish Geology Symposium, Abstracts, 24-28 September, 2001 Adana. p. 287.

8. Gürbüz, K. Kelling, G., 2001. Onlap Features of Eocene Carbonates in the Vicinity of Akçadağ (Malatya, Eastern Turkey). $4^{\text {th }}$ International Turkish Geology Symposium, Abstracts., 24-28 September, 2001 Adana. p. 288.

9. Aktimur, S., 1979. Malatya-Sivas Dolayının Uzaktan Algılama Yöntemiyle Çizgiselliklerinin Incelenmesi,. MTA Rapor No:66-51, Ankara.

10. Koçyiğit, A., Beyhan, A., 1998. A New Intracontinental Transcurrent Structure: the Central Anatolian Fault Zone, Turkey. Tectonophysics, 284, 317-336.

11. Westaway, R., Arger, J., 2001. Kinematics of the Malatya-Ovacik Fault Zone. Geodinamica Acta, 14, 103-131. 
12. Arpat, E., Şaroğlu, F., 1972. Doğu Anadolu Fayı ile ilgili Bazı Gözlem ve Düşünceler, MTA Dergisi, 78, 44-50, Ankara.

13. Şaroğlu, F., Emre, Ö., Boray, A., 1987. Türkiye Diri Fayları ve Depremsellikleri, MTA Rapor No: 8174, 377, (yayımlanmamış).

14. Kaymakçı, N., İnceöz, M., Ertepınar, P., 2006. 3d-Architecture-End and Neogene Evolution of the Malatya Basin: Inferences for the Kinematic of the Malatya and Ovacik Fault Zones, T.J.E.S, Vol: 15, 123-124, Ankara. 